\title{
Euler-Granular Approach for Modelling of Dilute Phase Pneumatic Conveying in a Vertical Pipe
}

\author{
Prasanna Welahettige $^{1} \quad$ W.K. Hiromi Ariyaratne ${ }^{1} \quad$ Morten C. Melaaen $^{1}$ \\ ${ }^{1}$ Faculty of Technology, Natural Sciences and Maritime Sciences, University College of Southeast Norway, Post box 235, \\ N-3603 Kongsberg, Norway, \{prasanna.welahettige, hiromi.ariyaratne, morten.c.melaaen\} @
}

usn. no

\begin{abstract}
In the present study, vertically upward dilute phase pneumatic conveying flow was predicted using EulerGranular method. Three dimensional computational fluid dynamics simulations were carried out for an $8 \mathrm{~m}$ long and $30.5 \mathrm{~mm}$ diameter circular pipe. The density of conveyed materials was $1020 \mathrm{~kg} / \mathrm{m}^{3}$. Simulations for different particle diameters; $200 \mu \mathrm{m}$ and $500 \mu \mathrm{m}$ were performed. The air velocities ranged from 9 to $17 \mathrm{~m} / \mathrm{s}$ and solid to air mass flow ratios ranged from 0.0 to 3.8. Pressure drop, air and particle velocity profiles and solid distribution profiles were studied and some of the results were compared with experimental data from existing literature. Predicted pressure drop and air velocity profiles are in good agreement with experimental results.
\end{abstract}

Keywords: Computational Fluid Dynamics, pneumatic conveying, pressure drop, velocity, solid distribution, experimental data

\section{Introduction}

Pneumatic conveying method is widely used for granular particles transport in cement, mining, petroleum and other industries. The materials are conveyed along horizontal and vertical distances; therefore the vertical upward flows can be expected in any industrial pneumatic conveying line. Vertical pneumatic flow is generally used in dilute phase pneumatic conveying systems (Haim et al, 2003). Particulate material transportation in suspension mode by employing gas which are at high velocities, is usually termed as dilute phase conveying (Ratnayake, 2005). In addition to the experimental studies, Computational Fluid Dynamics (CFD) modelling has been identified as a powerful and versatile tool for understanding the complex gas-solid interactions in a pneumatic conveying system (Ouyang et al, 2005). In general, there are two basic modelling approaches in use; Eulerian-Eulerian and Eulerian-Lagrangian. EulerGranular model is such an Eulerian-Eulerian model approach in where both gas and solid phases are treated as inter-penetrating continua (Ariyaratne et al, 2016a).
Several modelling studies have been performed previously for vertical pneumatic conveyors (Manjula et al, 2017). Azizi et al (2012) studied dense to dilute gassolid flow behavior in a vertical pneumatic conveyor. The turbulence interaction between gas and solid particles were investigated by using Simonin's and Ahmadi's models. Ahamdi's model predicted lower granular temperature and pressure drop compared to Simonin's model. According to their predictions, the minimum voidage and the maximum particle velocity in dilute phase were found along the centerline of the vertical pipe. It was showed that the solid phase turbulence plays a significant role in numerical predictions of pneumatic conveying of $1.91 \mathrm{~mm}$ particles and the capability of those models depends on tuning of the parameters of slip-wall boundary condition. The combined "Computational Fluid Dynamics - Discrete Element Method (CFD-DEM)" developed by Kuang et al (2009) gives satisfactory predictions for vertical pneumatic conveying characteristics. The mechanisms underlying the relation between pressure drop and gas velocity were analysed for dilute and dense phases. The forces that govern the flow of particles were investigated and a new phase diagram was established for the particular conveying system. Bilirgen et al (1998) used FLOW3D to determine vertical pipe flow characteristics and the pressure drop and velocity profiles were compared with available experimental data. Haim et al (2003) carried out a parametric study for dilute gas-particle flow in a vertical pipe using Eulerian-Lagrangian approach. It was concluded that the increase of Reynolds number, solid loading ratio, particle density and particle diameter increases the slip velocity and the acceleration length. Moreover, the pipe diameter has no significant effect on acceleration length and slip velocity as long as the particle mass flow rate and solid loading ratio are constant. The effects of different turbulent modulation models in vertical pipe pneumatic conveying were investigated by El-Behery et al (2011) using EulerianLagrangian approach. The effects of solid loading ratio and particle size on boundary layer thickness and pressure drop results were analysed. It was also 
identified that the concentration distribution is dependent on particle-particle collision, turbulence dispersion and lift force. Li et al (2013) carried out CFD-DEM simulations for a vertical pipe flow in order to investigate the effects of friction coefficient on pressure drop, solid concentration, the transition velocity from slug flow regime to dispersed flow regime and any reverse flow in the slug flow regime. In a previous study that was carried out by current authors, the sensitivity of a model parameter (specularity coefficient) on the predictions of pneumatic conveying characteristics in a vertical pipe was investigated (Ariyaratne et al, 2017).

In the current work, the characteristics of dilute upward vertical pneumatic conveying flow are investigated. The pressure drop, mean air and solid velocity profiles, solid distribution over the pipe cross section are studied for conveying of $200 \mu \mathrm{m}$ and $500 \mu \mathrm{m}$ diameter particles. Some of the simulation results are validated by experimental data from existing literature (Tsuji et al, 1984). The commercial CFD software ANSYS Fluent, version 16.2, was used for modelling and simulation. Steady state three-dimensional simulations were carried out using Euler-Euler approach for granular flows (Euler-Granular model).

\section{Numerical Model}

Both gas and solid phases are considered as continuous phases in Euler-Granular approach. Since the volume of a phase cannot be occupied by the other phases, the sum of volume fractions is equal to one. The steady state mass and momentum equations are solved for both gas and solid phases. To model the turbulent viscosity in the gas phase, the standard k-epsilon model is used. The Gidaspow model is used for the calculation of gas-solid exchange coefficient. The aerodynamic lift and vorticity induced lift force are calculated using Saffman-Mei model. The solid-phase stresses are derived by making an analogy between the random particle motion arising from particle-particle collisions and the thermal motion of molecules in a gas (kinetic theory of granular flow). Constitutive model from Lun et al. is used to calculate the solids pressure. The collisional and kinetic contributions are taken into account when modelling the solids shear viscosity. The bulk viscosity of solids is modeled through Lun et al. The equations of the models are not presented here and more details can be found elsewhere (Ariyaratne et al, 2016b).

\section{Computational Domain, Boundary Conditions and Material Properties}

ANSYS DesignModeler 16.2 and ANSYS Meshing 16.2 were used for the geometry drawing and mesh generation, respectively. The diameter of the vertical pipe is $30.5 \mathrm{~mm}$ which was selected based on the experimental setup used by Tsuji et al (1984). The simulated pipe length is $8 \mathrm{~m}$ which is a good enough length to achieve a fully developed flow situation. The gas-solid mixture enters from bottom of the pipe and leaves from top of the pipe. Figure 1 shows the mesh. The total number of elements in the mesh is 46080 and the maximum skewness is less than 0.39. The computational time is around $4 \mathrm{hrs}$ for a run when 2.4 $\mathrm{GHz}$ Intel ${ }^{\circledR}$ Xeon ${ }^{\circledR}$ processor and $32 \mathrm{~GB}$ installed memory are used.

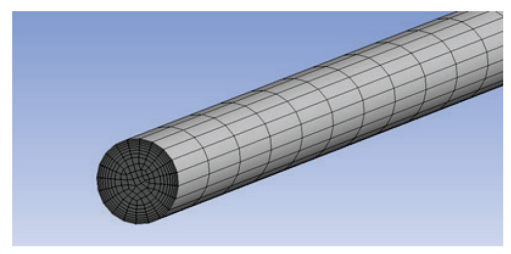

Figure 1. The mesh.

There are two types of boundary conditions, particularly for the gas phase and for the solid phase. Air and the solid particles enter to the pipe with similar and uniform velocities. The real velocities of air and particles and the solid volume fraction at the inlet defined for each case are shown in Table 1. The turbulence intensity of the air at the inlet is assumed as $10 \%$. Solid phase granular temperature at the inlet is calculated according to the formula mentioned by Patro and Dash (2014) and it is in the range of values between 0.44-0.49 for all the cases. The outlet is treated as a pressure outlet. The pipe wall is considered as hydrodynamically smooth and no-slip for the gas phase. Johnson and Jackson (1987) wall boundary condition is used for the solid phase. According to the recommendation from a previous study, the specularity coefficients 0.0001 and 0.0004 were selected for 200 $\mu \mathrm{m}$ and $500 \mu \mathrm{m}$ diameter particles, respectively (Ariyaratne et al, 2017). Coefficient of restitution for particle-wall collisions used in the simulations is 0.95 for all particle sizes.

The conveying medium is air which is having 1.225 $\mathrm{kg} / \mathrm{m}^{3}$ density and $1.7894 \times 10^{-5} \mathrm{~kg} / \mathrm{m} / \mathrm{s}$ viscosity. The particles are polystyrene particles which are having spherical shape and $200 \mu \mathrm{m}$ and $500 \mu \mathrm{m}$ diameters. The particle density is $1020 \mathrm{~kg} / \mathrm{m}^{3}$.

\section{Case Definition}

Table 1 shows the cases simulated in the present study. The cases are in accordance with experimental cases carried out by Tsuji et al (1984). The real air and particle velocities at the inlet ranged from 9 to $17 \mathrm{~m} / \mathrm{s}$ and the corresponding Reynolds numbers are $1.8 \times 10^{4}-3.6 \times$ $10^{4}$. The solid loading ratios are in the range of $0.0-3.8$ and the corresponding solid volume fractions at the inlet vary in between 0.0000 and 0.0045 . Coefficient of restitution for particle collisions used in all simulation cases is 0.9 . 
Table 1. Details of Simulated Cases.

\begin{tabular}{|l|l|l|l|l|l|l|}
\hline Case & $\begin{array}{l}\text { Particle } \\
\text { diameter } \\
(\mathrm{mm})\end{array}$ & $\begin{array}{l}\text { Real air } \\
\text { velocity at } \\
\text { the inlet } \\
(\mathrm{m} / \mathrm{s})\end{array}$ & $\begin{array}{l}\text { Real particle } \\
\text { velocity at } \\
\text { the inlet } \\
(\mathrm{m} / \mathrm{s})\end{array}$ & $\begin{array}{l}\text { Solid loading } \\
\text { ratio }(\mathrm{kg} \\
\text { solids/kg air) }\end{array}$ & $\begin{array}{l}\text { Solid volume } \\
\text { fraction at } \\
\text { the inlet }(-)\end{array}$ & $\begin{array}{l}\text { Reynolds } \\
\text { number of } \\
\text { the flow (-) }\end{array}$ \\
\hline Case -1.1 & 0.5 & 10.5795 & 10.5795 & 3.4 & 0.00407 & $2.2 \times 10^{4}$ \\
\hline Case -1.2 & 0.5 & 10.5731 & 10.5731 & 2.9 & 0.00347 & $2.2 \times 10^{4}$ \\
\hline Case -1.3 & 0.5 & 10.5630 & 10.5630 & 1.3 & 0.00156 & $2.2 \times 10^{4}$ \\
\hline Case -1.4 & 0.5 & 10.5529 & 10.5529 & 0.0 & 0.00000 & $2.2 \times 10^{4}$ \\
\hline Case -2.1 & 0.5 & $8.9200-$ & $8.9200-$ & $2.0-3.8$ & $0.00230-$ & $1.8 \times 10^{4}-$ \\
\hline Case -3.1 & 0.2 & 17.1800 & 17.1800 & & 0.00450 & $3.6 \times 10^{4}$ \\
\hline Case -3.2 & 0.2 & 11.0577 & 11.0577 & 3.2 & 0.00383 & $2.3 \times 10^{4}$ \\
\hline Case -3.3 & 0.2 & 11.0405 & 11.0405 & 1.9 & 0.00228 & $2.3 \times 10^{4}$ \\
\hline Case -3.4 & 0.2 & 11.0154 & 11.0154 & 0.0 & 0.00060 & $2.3 \times 10^{4}$ \\
\hline
\end{tabular}

\section{Results and Discussion}

The predicted pressure drop profiles, particle and air velocity profiles and solid distribution profiles for two different particle sizes and for different solid loading ratios are presented for the vertical upward pneumatic conveying system. The pressure drop profiles do not include the hydrostatic pressure. The mean air and particle velocity profiles and the solid volume fraction profiles (Figure 4, Figure 5, Figure 6 (a) and Figure 7) are taken along a diameter of pipe cross section at $7.5 \mathrm{~m}$ height from the bottom of the pipe which ensures the fully developed profiles. Some of the profiles are compared with experimental results from Tsuji et al (1984)

Figure 2 shows the simulated pressure profiles along the pipe axis for $500 \mu \mathrm{m}$ diameter particles for a certain superficial air velocity but for different solid loading ratios. The pressure drop has been increased from 457 $\mathrm{Pa}$ to $786 \mathrm{~Pa}$ in the entire pipe when the solid loading ratio is increased from 0.0 to 3.4. The total pressure drop can be considered as the summation of gas phase pressure drop and solid phase pressure drop (Ratnayake et al, 2007). When the solid loading ratio is increased by increasing the solid mass flow rate, the work that should be done by unit mass of air on particles is increased. In the same time, the higher solid mass flow rate increases the particle number density in the system which in turn increases the collisions between particle-particle and particle-wall hence the pressure drop.

Figure 3 shows the pressure drop dependence of 500 $\mu \mathrm{m}$ diameter particles on inlet air velocity for the solid mass flow rate of $0.03 \mathrm{~kg} / \mathrm{s}$. In contrast to the Figure 2, the pressure drop increases when solid loading ratio is

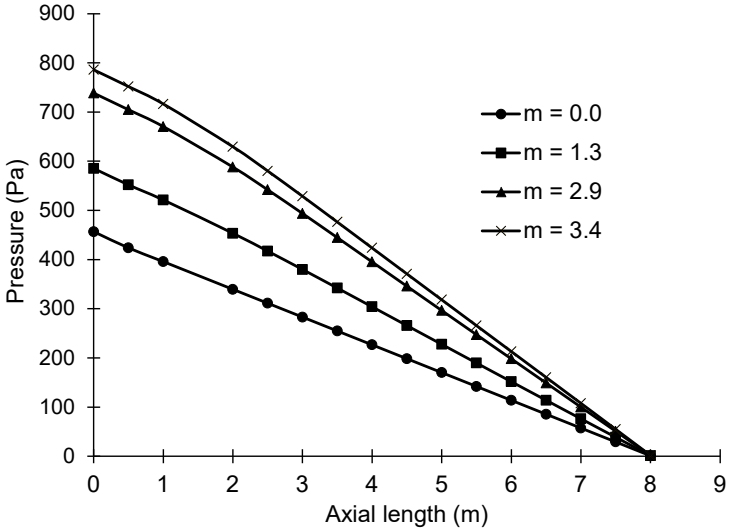

Figure 2. Axial static pressure variation for particle diameter $500 \mu \mathrm{m}$ and $\mathrm{Re}=2.2 \times 10^{4}$ (from Case-1.1 to Case-1.4).

decreased (the solid loading ratio is decreased when increasing air velocity by keeping the solid mass flow rate constant). Similar to the explanation for Figure 2, the work that should be done by unit mass of air in order to move the particles ahead is decreased when the air velocity is increased; hence the pressure drop is decreased. Nevertheless, the pressure drop increases with increased air velocity due to increase of gas phase shear similar to a single phase flow (Azizi et al, 2012). The latter is dominant compared to former; hence the result is increase of pressure drop with increase of air velocity.

The predicted results are compared with experimental data from Tsuji et al (1984) and it shows a good agreement. The difference between experimental and predicted results is in the range of $9-19 \%$. It should be noted that the simulations are carried out with 
specularity coefficient 0.0004 and the pressure drop prediction is significantly sensitive to this parameter (Ariyaratne et al, 2017).

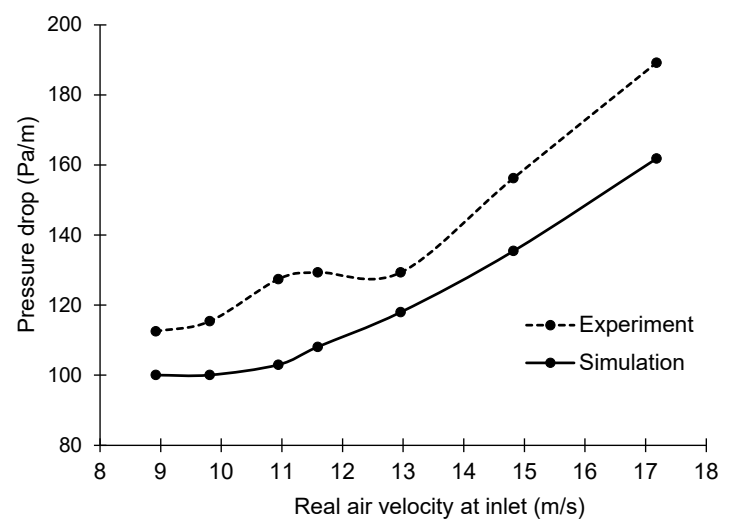

Figure 3. Comparison of simulated pressure drops with experimental data for particle diameter $500 \mu \mathrm{m}$ and solid mass flow rate $0.03 \mathrm{~kg} / \mathrm{s}$ (Case-2.1).

In general, Patro and Dash (2014) who used EulerGranular method to predict vertical pipe pneumatic conveying have shown that the pressure drop depends on gas phase Reynolds number, solid loading ratio, particle diameter and density and on model collision coefficients such as specularity coefficient.

The predicted real mean air velocity profiles along a diameter in a pipe cross section at fully developed

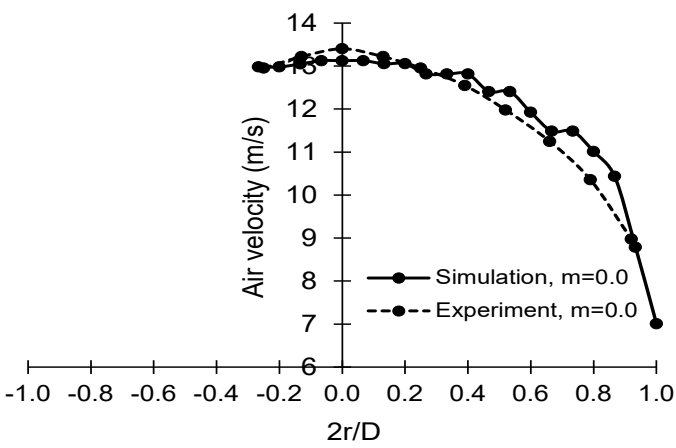

(a)

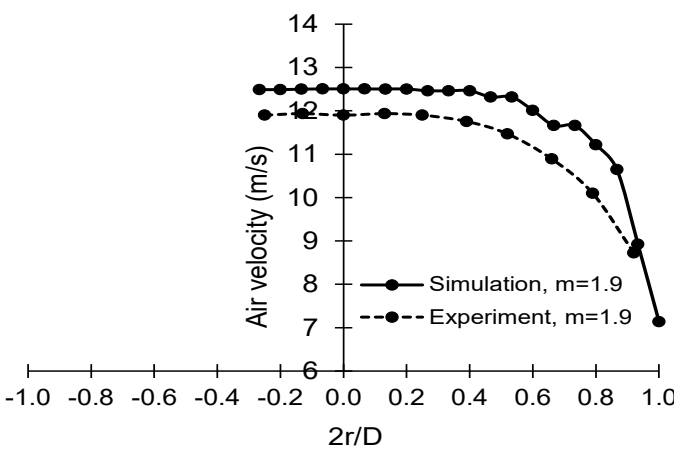

(c) region are shown in Figure 4 and Figure 5 for $200 \mu \mathrm{m}$ and $500 \mu \mathrm{m}$ diameter particles and for different solid loading ratios. The profiles are also compared with the experimental data (Tsuji et al, 1984).

Since the Reynolds number of the flow is around 22000 , the single phase velocity profiles should show a turbulence behavior ((a) in both figures). Inclusion of solids into the system changes the air velocity profile remarkably for both particle sizes. In general, the air velocity gets reduced with increase of solid loading ratio because of the increased drag. Moreover, the air velocity profiles become more flattened with increased solid loading ratios (e.g. $\mathrm{m}=1.9$ and $\mathrm{m}=3.2$ ) for $200 \mu \mathrm{m}$ diameter particles (Figure 4). Tsuji et al (1984) also have observed increase of turbulence intensity in core region of the pipe when the loading is increased from 1.3 to 3.2 for $200 \mu \mathrm{m}$ diameter particles. The effect of particles on air velocity profiles is more significant for larger particles (500 $\mu \mathrm{m}$ diameter), in where the profile becomes concave when increasing the solid loading ratio (Figure 5). This is reasonable as the larger particles restrict the air flow more than that of the smaller particles.

The agreement between experiments and predictions are significantly good for single phase flows. The deviation between experiments and predictions becomes larger when increasing the solid loading ratio for 200

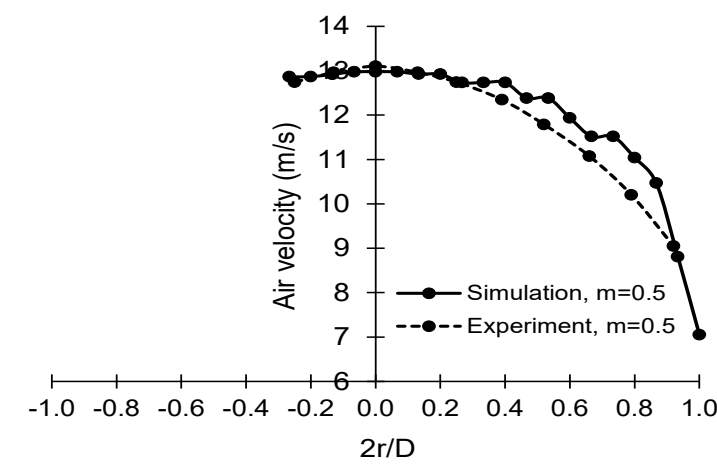

(b)

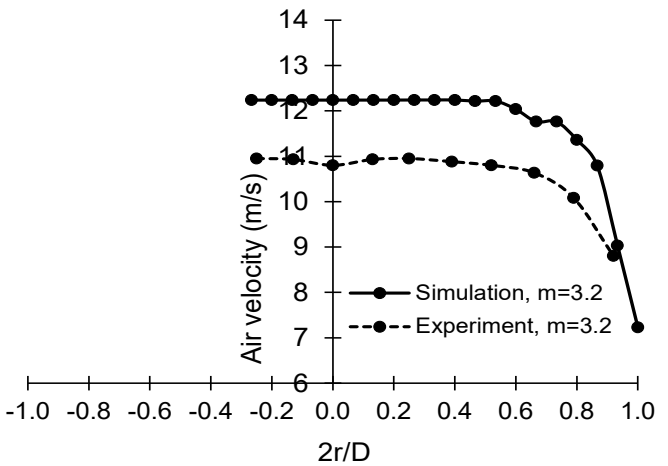

(d)

Figure 4. Comparison of predicted and experimental mean real air velocity profiles along a diameter in a pipe cross section at fully developed region for particle diameter $200 \mu \mathrm{m}$ and $\mathrm{Re}=2.3 \times 10^{4}$ (from Case3.1 to Case-3.4). 


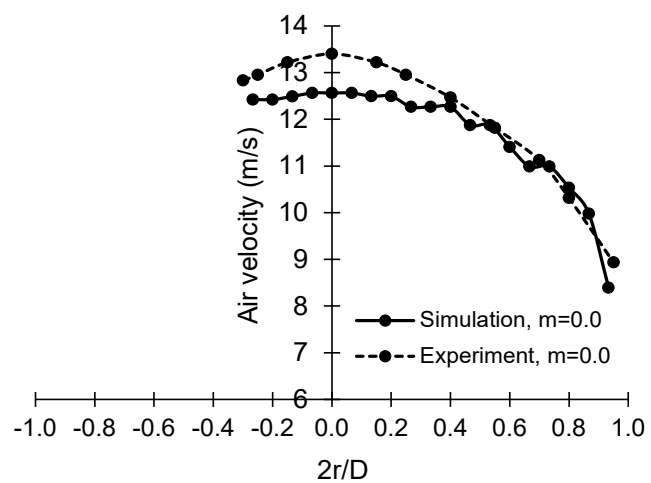

(a)

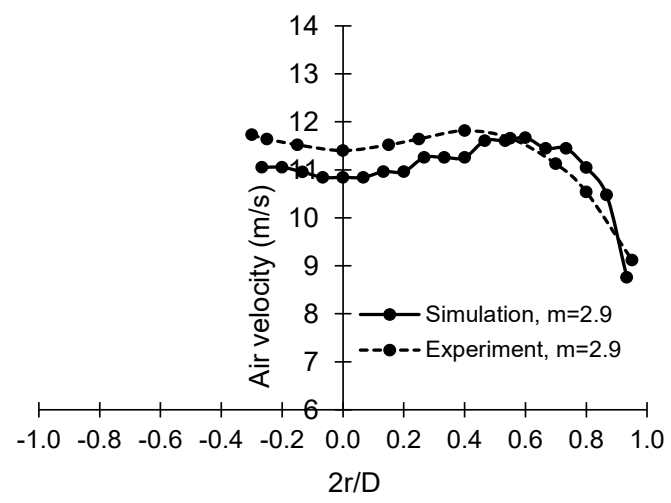

(c)

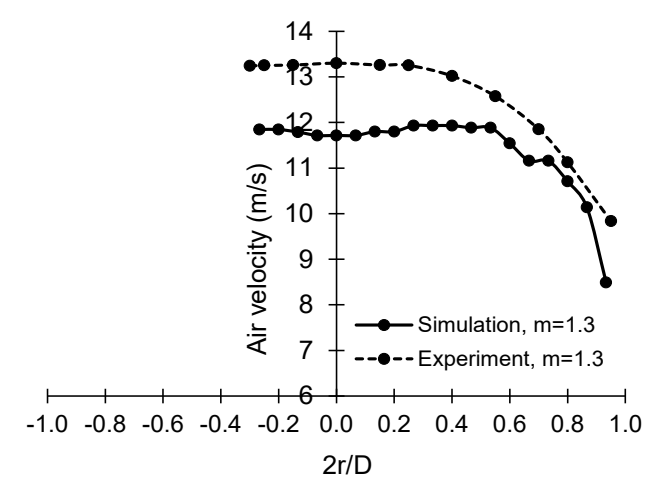

(b)

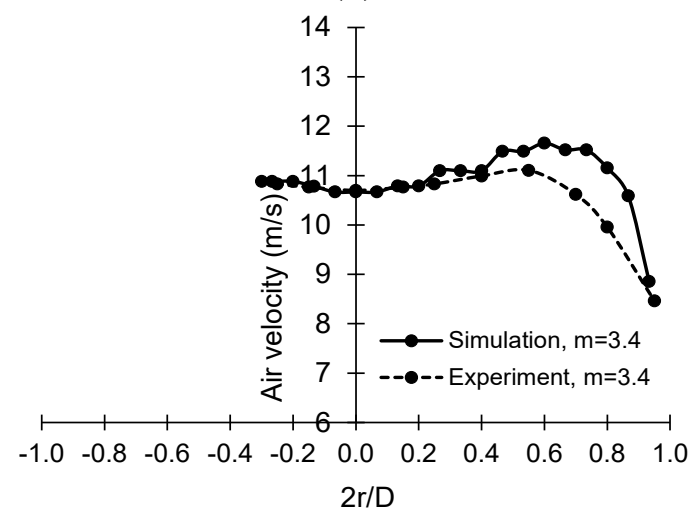

(d)

Figure 5. Comparison of predicted and experimental mean real air velocity profiles along a diameter in a pipe cross section at fully developed region for particle diameter $500 \mu \mathrm{m}$ and $\mathrm{Re}=2.2 \times 10^{4}$ (from Case1.1 to Case-1.4).

$\mu \mathrm{m}$ diameter particles (Figure 4). However, the agreement between experimental and predicted results is good for $500 \mu \mathrm{m}$ diameter particles for the range of solid loading ratios studied (Figure 5). For the highest solid loading ratio (3.4), the maximum velocity predicted by the model is higher than that of the experiments and the experimental maximum is located at around $2 \mathrm{r} / \mathrm{D}=0.5$ while the predicted maximum is located at around $2 \mathrm{r} / \mathrm{D}=0.6$. In general, having lower velocities in core region compared to annulus region is better explained by solid distribution profiles (Figure 6 (a)).

The predicted solid volume fractions along a diameter in a pipe cross section at fully developed region for $500 \mu \mathrm{m}$ diameter particles and for different solid loading ratios are shown in Figure 6 (a). It shows that the highest concentration of the solid particles is located in the central part of the pipe cross section. Due to roughness of the wall, the rebound angle of particles increases resulting in particle movement into core region of the pipe. The solid concentration in central region is further increased when increasing the solid mass flow rate (i.e. the solid loading ratio). This is the reason for having lower air velocities in the core region of the pipe (Figure 5). Nevertheless, the extremely low solid concentration nearby walls is peculiar.
Figure 6 (b) shows the solid volume fraction variation along the central axis of the vertical pipe. At steady state, from inlet $(z=0 \mathrm{~m})$ to the outlet $(\mathrm{z}=8 \mathrm{~m})$, the solid volume fractions have been increased for all solid loading ratios tested. The particles might tend to move to the core region of the pipe cross section when the particles move along the pipe. However, the reasons for the observation should be further investigated.

Figure 7 shows the predicted particle velocity profiles corresponding to Case 1-1, Case 1-2 and Case 1-3. The air velocities corresponding to these cases are shown in Figure 5. The particle velocities are lower than the air velocities providing drag force to move the particles ahead. When solid loading ratio is increased by increasing solid mass flow rate, the particle velocity is reduced because the work that is done by unit volume of gas on unit mass of particles gets reduced. Moreover, the profiles become concave with increased solid input. The maximum velocities are located in the range of $2 \mathrm{r} / \mathrm{D}=$ 0.5-0.6 for the solid loading ratios, 2.9 and 3.4. The higher particle concentration in the core region of the pipe might restrict the flow of the particles resulting in lower particle velocity in the core region of the pipe cross section. 


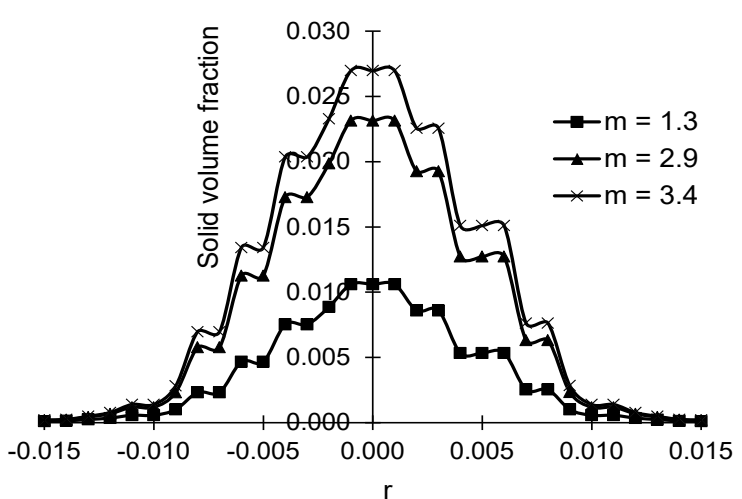

(a)

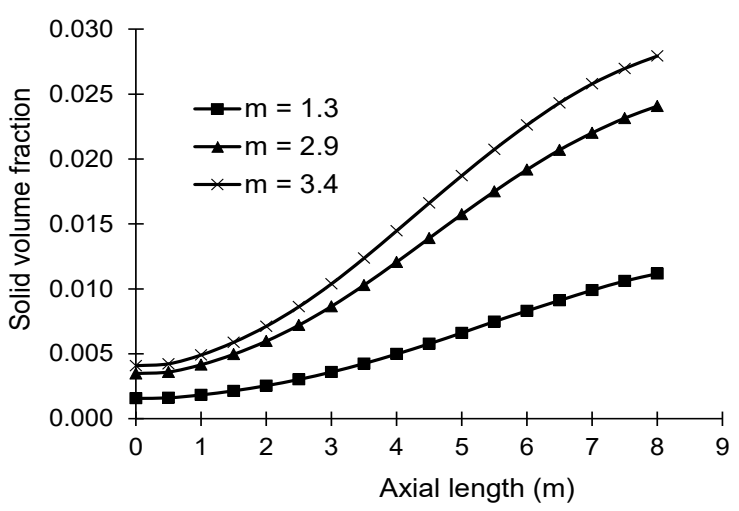

(b)

Figure 6. Solid volume fraction along a diameter in a pipe cross section at fully developed region (a) and solid volume fraction along the pipe axis (b) for particle diameter $500 \mu \mathrm{m}$ and $\mathrm{Re}=2.2 \times 10^{4}$ (Case-1.1 to Case-1.3).

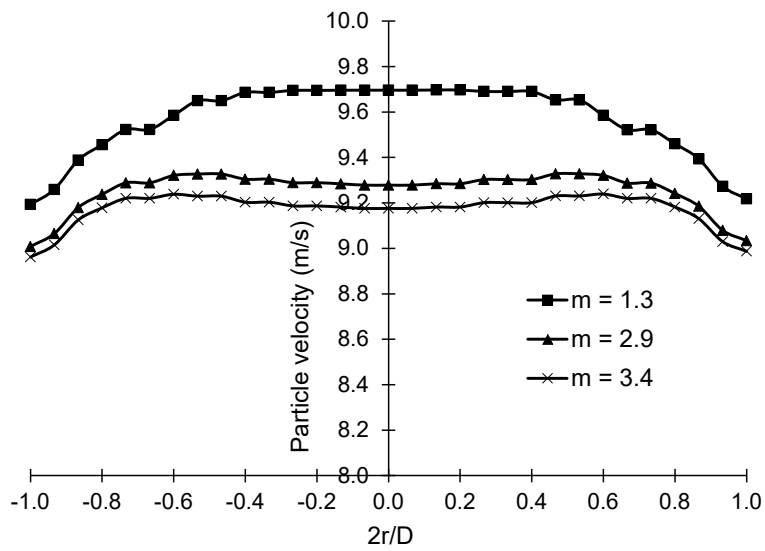

Figure 7. Mean real particle velocity profiles along a diameter in a pipe cross section at fully developed region for particle diameter $500 \mu \mathrm{m}$ and $\mathrm{Re}=2.2 \times 10^{4}($ Case- 1.1 to Case-1.3).

\section{Conclusion}

Euler-Granular approach is used to study the pneumatic conveying characteristics of dilute phase vertical upward flow. Cases with different operating conditions and particle diameters are simulated and some of the results are compared with experimental data from the existing literature. The pressure drop profiles, air and particle velocity profiles and solid distribution profiles are analysed.

The pressure drop results show good agreement with experimental data for $500 \mu \mathrm{m}$ diameter particles and the deviation between experimental and predicted pressure drops is in the range of $9-19 \%$. The prediction of air velocity profiles is also good; however the deviation is increased when the solid loading ratio is increased for $200 \mu \mathrm{m}$ particles. At the higher solid loading ratios tested, the air velocity profiles become concave for 500 $\mu \mathrm{m}$ diameter particles. A higher solid concentration could be observed in the core region of the pipe cross section. However no experimental data is available to validate solid distribution. Finally, it should be noted that the specularity coefficient used in Johnson and Jackson particle-wall boundary conditions in the present model has significant effects on the predictions and the predictions made here is by using certain specularity coefficient values.

\section{Nomenclature}

D Pipe diameter, $(\mathrm{m})$

$\mathrm{m}$ Solid loading ratio (solid mass flow rate/air mass flow rate), (-)

Re Reynolds number of the flow, (-)

$\mathrm{r}$ Horizontal distance from pipe vertical axis, (m)

$\mathrm{z} \quad$ Vertical distance from the pipe inlet, (m)

\section{Acknowledgements}

The authors would like to acknowledge the financial support provided by the Research Council of Norway under PETROMAKS II program and Aker BP ASA for the scientific investigation.

\section{References}

W. K. H. Ariyaratne, E. V. P. J. Manjula, C. Ratnayake and M. C. Melaaen. CFD Approaches for Modeling Gas-Solids Multiphase Flows - A Review, in: Proceedings of EUROSIM 2016, September 13-16 2016 Oulu, Finland. Published by IEEE, ISBN 978-1-5090-4119-0, pp. 629634; http://eurosim2016.info, 2016a.

W. K. H. Ariyaratne, C. Ratnayake and M. C. Melaaen. Eularian-Eularian Approach for Modeling Dilute Phase Pneumatic Conveying in a Horizontal Pipe. Proceedings of ICBMH 2016 July 11-14 2016, Darwin, Australia, pp. 409$416,2016 \mathrm{~b}$

W. K. H. Ariyaratne, P. Welahettige and M. C. Melaaen. A parametric study for Euler-Granular model in dilute phase vertical pneumatic conveying. International Journal of Computational Methods and Experimental Measurements, 2017, accepted.

S. Azizi, D. Mowla and G. Ahmadi. Numerical evaluation of turbulence models for dense to dilute gas-solid flows in 
vertical conveyor. Particuology, 10 (5): 553-561, 2012. doi: 10.1016/j.partic.2011.12.006.

H. Bilirgen, E. Levy and A. Yilmaz. Prediction of pneumatic conveying flow phenomena using commercial CFD software. Powder Technology, 95 (1): 37-41, 1998. doi: 10.1016/S0032-5910(97)03313-5.

S. M. El-Behery, W. A. El-Askary, M. H. Hamed and K. A. Ibrahim. 2011. Hydrodynamic and thermal fields analysis in gas-solid two-phase flow. International Journal of Heat and Fluid Flow, 32 (3): 740-754, 2011. doi: 10.1016/j.ijheatfluidflow.2011.02.003.

Fluent. ANSYS Fluent theory guide. ANSYS, Inc.2013.

D. Gidaspow, R. Bezburuah and J. Ding. Hydrodynamics of circulating fluidized beds: Kinetic theory approach. Proceedings of 7th international conference on fluidization, Gold Coast (Australia), 3-8 May 1992.

M. Haim, Y. Weiss and H. Kalman. Turbulent Gas-Particles Flow in Dilute State: A Parametric Study. Particulate Science and Technology, 21 (1): 1-24, 2003. doi: 10.1080/02726350307498.

P. C. Johnson and R. Jackson. Frictional-collisional constitutive relations for granular materials, with application to plane shearing. Journal of Fluid Mechanics, 176: 67-93, 1987. doi:10.1017/S0022112087000570.

S. B. Kuang, A. B. Yu and Z. S. Zou. Computational Study of Flow Regimes in Vertical Pneumatic Conveying. Industrial \& Engineering Chemistry Research, 48 (14): 6846-6858, 2009. doi:10.1021/ie900230s.

K. Li, S. B. Kuang, R. P. Zou, R. H. Pan and A. B. Yu. Numerical study of vertical pneumatic conveying: Effect of friction coefficient. AIP Conference Proceedings, 1542 (1): 1154-1157, 2013. doi:10.1063/1.4812141.

C. K. K. Lun, S. B. Savage, D. J. Jeffrey and N. Chepurniy. Kinetic theories for granular flow: inelastic particles in Couette flow and slightly inelastic particles in a general flow field. Journal of Fluid Mechanics, 140: 223-256, 1984. doi: $10.1017 / \mathrm{S} 0022112084000586$.

E. V. P. J. Manjula, W. K. H. Ariyaratne, C. Ratnayake and M. C. Melaaen. A review of CFD modelling studies on pneumatic conveying and challenges in modelling offshore drill cuttings transport. Powder Technology, 305: 782-793, 2017. doi:10.1016/j.powtec.2016.10.026.

S. Ogawa, A. Umemura and N. Oshima. On the equations of fully fluidized granular materials. Zeitschrift für angewandte Mathematik und Physik, ZAMP 31 (4): 483493, 1980. doi:10.1007/BF01590859.

J. Ouyang, A. B. Yu and R. H. Pan. Simulation of gas-solid flow in vertical pipe by hard-sphere model. Particulate Science and Technology, 23: 47-61, 2005. doi:10.1080/02726350590902479.

P. Patro and S. K. Dash. Two-fluid modeling of turbulent particle-gas suspensions in vertical pipes. Powder Technology, 264: 320-331, 2014. doi:10.1016/j.powtec.2014.05.048.

C. Ratnayake. A comprehensive scaling up technique for pneumatic transport systems. $\mathrm{PhD}$ thesis, Telemark University College, Norway, 2005.

C. Ratnayake, B. K. Datta and M. C. Melaaen. A Unified Scaling-Up Technique for Pneumatic Conveying Systems.
Particulate Science and Technology, 25 (3): 289-302, 2007, doi:10.1080/02726350701375949.

M. Syamlal, W. Rogers and T. J. O'brien. MFIX Documentation; Theory Guide. National Technical Information Service, Springfield, 1993.

Y. Tsuji, Y. Morikawa and H. Shiomi. LDV measurements of an air-solid two-phase flow in a vertical pipe. Journal of Fluid Mechanics, 139: 417-434, 1984, doi:10.1017/S0022112084000422. 